\title{
A new simplified model for evaluating thermal environment and thermal sensation: An approach to avoid occupational disorders
}

\author{
Mariana Morgado a, Mário Talaia ${ }^{\mathrm{b}}$, Leonor Teixeira ${ }^{\mathrm{c}, *}$ \\ a Department of Economics, Management and Industrial Engineering (DEGEI), University of Aveiro, 3810-193 Aveiro, Portugal \\ ${ }^{\mathrm{b}}$ Department of Physics (DFIS), Research Center in Teaching and Technology in Training of Trainers (CIDTFF), University of Aveiro, 3810-193 Aveiro, Portugal \\ ${ }^{\mathrm{c}}$ Department of Economics, Management and Industrial Engineering (DEGEI), Institute of Electronics and Telematics Engineering of Aveiro (IEETA), \\ University of Aveiro, 3810-193 Aveiro, Portugal
}

\section{A R T I C L E I N F O}

\section{Article history:}

Received 30 July 2014

Received in revised form

5 October 2015

Accepted 7 November 2015

Available online $\mathrm{xxx}$

\section{Keywords:}

Ergonomics

Work-related disorders

Thermal comfort

Thermal indexes

Thermal sensation

EsConTer index

\begin{abstract}
A B S T R A C T
Thermal heat stress is a cause of many occupational disorders that disrupt worker performance and the quality of work and, in extreme cases, can lead to death. In the industrial context, thermal discomfort is cited as one of the major causes of dissatisfaction in workplaces when people are exposed to extremely hot or cold thermal environments. Given the time that people spend in their workplaces, studies evaluating the comfort of the thermal environment are becoming increasingly important. However, comfort evaluation studies are time-consuming and for many organizations become expensive and difficult to implement due to the lack of a simplified model for evaluating the thermal environment of workplaces and the thermal sensations of their occupants.

This paper aims to show the possibility of assessing the thermal patterns of industrial spaces and consequently identifying the most critical areas in terms of thermal comfort, using thermal indexes supported by real data collected using inexpensive measuring tools. This study was carried out in two Portuguese industrial manufacturing facilities with different characteristics, evaluating the thermal environment and the workers' thermal sensation in the season of spring. The data related to environmental parameters were collected using two similar measuring instruments, Testo 435-4 and Center 317temperature humidity meter, while the workers' thermal sensations were collected using a thermal sensation colour scale that is aligned with the ASHRAE seven-point thermal sensation scale. The results were reproduced in colour maps based on MatLab algorithms, using the calculation formula of three thermal indexes, EsConTer (a new index), THI, and PPD.

The applied methodology, using the EsConTer index, proved to be an interesting method for easily studying thermal environments and predicting the thermal comfort of an indoor space. Moreover, the representation of thermal indexes in colour maps is an informative approach, prompting recommendations and development actions with the aim of providing more comfortable, safer, and healthier work conditions, and minimizing occupational disorders. Indeed, the practical results were appreciated by the Health and Safety Department of each industry in order to develop measures that improve the occupational health of the occupants to prevent work accidents and work-related disorders.

Accordingly, the methodology applied in this work, using a colour scale with the EsConTer index, proposes a new, simplified model for thermal stress risk evaluation, aiming to minimize difficult and time-consuming investigations to identify thermal comfort problems in workplaces. The coloured maps generated by MatLab algorithms proved to be a useful tool to visualize the thermal pattern of an environment, and consequently to identify thermal comfort problems.
\end{abstract}

() 2015 Elsevier B.V. All rights reserved.

\footnotetext{
* Corresponding author. University of Aveiro, Campus Universitário de Santiago, 3810-193 Aveiro, Portugal.

E-mail address: Iteixeira@ua.pt (L. Teixeira).
}

\section{Introduction}

The work environment is defined as a set of surrounding elements which influences the workers' tasks at their workstations. Ergonomics is the scientific discipline that studies workplaces in 
order to adapt workstations to workers' welfare needs. It aims to understand the interactions and the relationship between the workers and their work environment, and create workstations with the required conditions to achieve high performance and prevent work-related disorders (Guimarães et al., 2015; IEA, 2014; Wisner, 1992).

Work-related disorders, also known as occupational diseases, are unexpected and unplanned occurrences which arise in connection with work, leading to personal injury, disease, or death (Zhou et al., 2014). These disorders may be divided into different categories, such as mental disorders, noise-induced hearing loss, respiratory diseases, cardiovascular diseases, infectious and parasitic diseases, and musculoskeletal disorders (MSDs). Roman-liu (2013) states that a wide range of external factors in the work environment cause musculoskeletal disorders, one of the most widespread occupational pathologies (Chiasson et al., 2012; Zare et al., 2015). MSDs are developed when work demands exceed the worker's ability, i.e., the cumulative effect to the worker when under protracted load work, such as repetitive motion, excessive force, awkward or sustained postures, or prolonged sitting and standing (Ogg, 2011; Roman-liu, 2013; Costa and Vieira, 2010). These types of disorders are, citing Costa and Vieira (Costa and Vieira, 2010), associated with injuries or dysfunctions affecting muscles, bones, nerves, tendons, ligaments, joints, cartilages, and spinal discs.

There are several studies that demonstrate a strong relationship between comfort, health, environment control in indoor spaces, and productivity in workplaces (Akimoto et al., 2010; Bluyssen et al., 2011; Escorpizo, 2008; Lan et al., 2011; Mohamed and Srinavin, 2002; Wagner et al., 2007). One of the crucial human requirements is a working environment that allows people to perform their work optimally under comfortable conditions (Lan et al., 2011). Furthermore, citing Huizenga et al. (2006), the major cause of dissatisfaction in workplaces is thermal discomfort.

Thermal discomfort, also termed thermal stress, corresponds to a dissatisfied state on the part of a person in terms of their thermal sensation, when exposed to extremely hot or cold thermal environments (ASHRAE 55, 2010; Teixeira et al., 2014). Thermal discomfort may be felt all over or in a particular part of the body (ASHRAE, 2001; Bluyssen et al., 2011; Yigit et al., 2015). This thermal state may reduce productive capacity or cognitive and physical performance, increasing the likelihood of fatigue and injury to workers and workplace accidents (ASHRAE, 2001; Bröde et al., 2013; Jackson and Rosenberg, 2010; Riniolo and Schmidt, 2006). Thus, extreme thermal stress is related to many work-related diseases associated with all categories of occupational disease, for example skin lesions, heat stroke, hyperthermia, heat exhaustion, heat cramps, heat syncope, heat rash, and human body collapse (ASHRAE, 2001; Jackson and Rosenberg, 2010).

According to Cox (2005) a healthy environment can be found when the combined physical, chemical, and biological properties do not cause or aggravate any of the workers' diseases, ensuring high levels of comfort and contributing to the best performance in executing their functions or tasks.

In this context, the scientific literature shows that research on the thermal environment in workstations is necessary, as individuals spend most of their time at work (Felix et al., 2010; Wisner, 1992). Thus, an understanding of the adaptation of individuals to the workstation and their reaction to different thermal environments is very important (Emmanuel, 2005). Furthermore, most of the studies in the scientific literature analyse work environments using thermal indexes, such as Wet-Bulb Globe Temperature (WBGT) (ISO 7243, 1989), Equivalent Temperature (ET) (Matzarakis et al., 1999), Relative Strain Index (RSI) (Lee and Henschel, 1963), Temperature-Humidity Index (THI) (Nieuwolt,
1977), Predicted Mean Vote (PMV), and Predicted Percentage Dissatisfied (PPD) (ISO 7730, 2006). PMV and PPD are examples of indexes which take into consideration the individual's thermal sensation, which would seem to suggest a better approach to a given thermal environment. However, according to the methodology applied in most case-studies reported in the literature, it is difficult to understand the thermal patterns of an indoor space using cheap and easy measuring tools which also take into account the thermal sensation of its occupants. In fact, the subjectivity associated with the thermal sensation concept hinders an objective analysis of thermal comfort that allows the creation of indoor spaces which satisfy most of the population who occupy them (Arezes et al., 2013; Bröde et al., 2013; De Giuli et al., 2014; Oliveira et al., 2014).

It should be noted that the study of the thermal environment, instigated by Fanger (1972) and associated with ergonomics, is mainly considered as a corrective and reactive intervention because it is usually applied to existing situations.

This paper aims to show the possibility of ascertaining the thermal patterns of industrial spaces and consequently identifying the most critical areas in terms of thermal comfort using thermal indexes supported by real data collected using inexpensive measuring tools. This study was carried out in two Portuguese industrial manufacturing facilities with different characteristics, evaluating the thermal environment and the workers' thermal sensation in the season of spring. The results were reproduced in colour maps based on MatLab algorithms, using the calculation formulas of three different thermal indexes - EsConTer, THI, and PPD.

\section{Material and methods}

The present study was carried out in two Portuguese manufacturing industries with different characteristics, but both associated with heat thermal stress. The first industry (designated by IND_1) is a metalworking company that belongs to a giant German group with many companies all over the world. The second industry (designated by IND_2) is a family business associated with traditional glass production in Marinha Grande. In this section the methodology used in the present work will be briefly described, explaining the procedures followed to collect data, analyse information, and interpret the results.

\subsection{Measurement of environmental parameters}

This study comprised measurements of environmental parameters and investigation of workers' subjective sensations in two different industrial facilities in spring.

Firstly, in order to gather indoor environmental parameters, the layouts of both interior spaces were analysed with the purpose of identifying the observation points which were to be used to collect data. Fig. 1 presents the layout of the studied areas and the respective points of observation selected for IND_1 (on the left) and for IND_2 (on the right). These areas were selected according to the recommendations of the directors of the respective companies. In the layout, the $\mathrm{x}$ and $\mathrm{y}$ axes represent the dimensions of the study areas in metres $(\mathrm{m})$, and the numbered circles represent the places where the measurement was made (i.e. the points of observation) in each case-study. As can be seen in Fig. 1, in IND_1 seventy-four points of observation were identified, seventy-two (from 1 to 72 : blue circles) inside the study area, and two (73 and 74: grey circles) outside the study area; in IND_2 forty points of observation were identified, thirty-six inside the study area (from 1 to 36: blue circles) and four outside the study area (from 37 to 40: grey discs). The measurements outside of the study area were required because the 

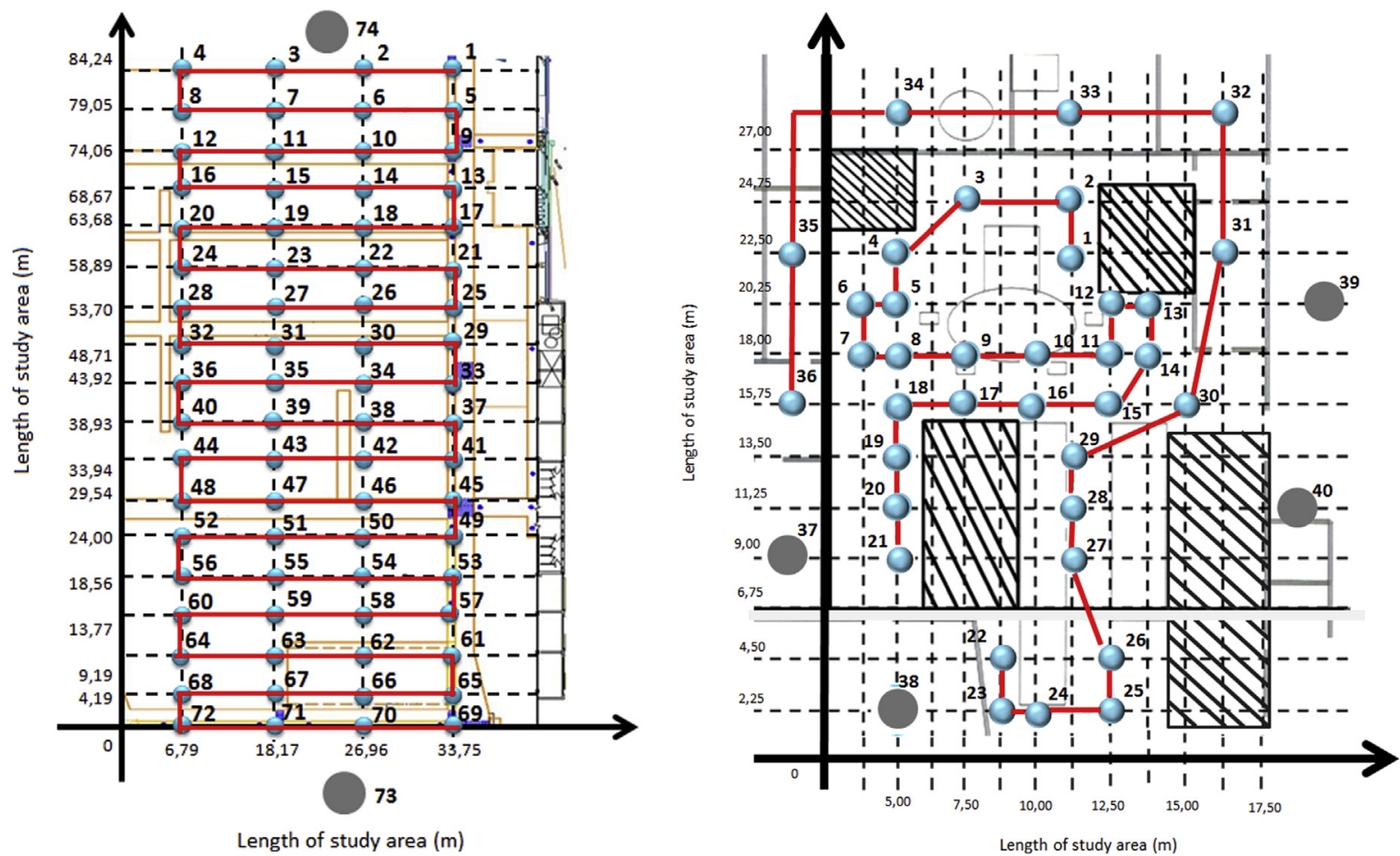

Fig. 1. Layout of study area of IND_1 (left) and IND_2 (right).

thermal environment in the area under study is greatly influenced by the surrounding environment that lies just outside it.

The measurements made at each point of observation were not taken at the same time due to measuring instrument restrictions. To collect measurements at all points at the same time, it would be necessary to have a sensor network or an expensive BABUC measuring instrument. In this project, accurate, calibrated, and cheap instruments were used which only collected data from one station at a time. Because of this, the observer had to make two symmetrical paths in order to understand the oscillations in the thermal pattern in the study areas during the period of measurement. In Fig. 1, the path (one way) is represented by the lines linking the points of observation inside the study areas. After confirming that no difference existed between the patterns of data collected in both directions (following two symmetrical consecutive paths), the data began to be collected based on one way only. Also, in the points of observation outside the study areas, data were collected right before and after each path.

Data was collected with two similar measuring instruments, a Testo 435-4 and a Center 317- temperature humidity meter, with the aim of validating data collected and avoiding possible technological problems. These two instruments are multifunction gauges of air quality which allow the collection and storage of a wide range of thermal variables. At each point of observation, the measuring instruments were positioned in accordance with ISO 7726 (2001), $1.10 \mathrm{~m}$ above the floor. The measurements were made at two times, in the morning (around 10 a.m.) and in the afternoon (around 3 p.m.), in order to understand the influence of the diurnal cycle in the study areas.

Concerning the environmental parameters collected, since thermal environment is characterized as a set of thermal variables surrounding a person which may influence her/him directly and/or indirectly (including air temperature, air velocity, relative humidity, among others), in this project data about air temperature $-\mathrm{T}\left({ }^{\circ} \mathrm{C}\right)$, relative humidity - $\mathrm{RH}(\%)$, and wet-bulb temperature - WBT (\%) was collected. To validate the data collected by the measuring instruments, the SPRUNG formula was applied, using the input values of $\mathrm{T}\left({ }^{\circ} \mathrm{C}\right)$ and $\mathrm{RH}(\%)$ and obtaining the WBT (\%). The relative error that occurred between measured value and calculated value of WBT was less than $0.5 \%$.

Furthermore, in order to authenticate the outdoor data collected from both industrial spaces, weather charts as well as air temperature and relative humidity graphics were downloaded from the Instituto Português do Mar e da Atmosfera (IPMA) website (https:// www.ipma.pt). These weather charts provided information about the meteorological elements in the regions where the study companies are located, in order to understand the behaviour of the atmosphere on each day of measurement. The air temperature and relative humidity graphics were crucial to compare the outdoor values collected during the study to the values gathered by meteorological stations, in order to validate the measuring instruments.

\subsection{Thermal indexes to study the thermal patterns in indoor spaces}

Existing methods for thermal comfort evaluation often require sophisticated measuring instruments, which are not always accessible to a large proportion of small and medium-sized enterprises.

In this study a new simplified model, EsConTer, will be presented, which has shown good results and in addition uses input parameters collected with cheap and easy-to-use measuring instruments. The EsConTer index, developed by Talaia and Simões (2009), has demonstrated its versatility and ease of application with regard to the analysis of thermal comfort (Morgado et al., 2015; Talaia et al., 2013; Teixeira et al., 2014). In order to validate the results of this new model, THI, a thermal index present in several studies related to thermal comfort, was applied. Additionally, the PPD index was also used, once its results had been aligned with the ASHRAE seven-point thermal sensation scale.

EsConTer is a very recent thermal index which is presented in the form of a thermal scale (Ter) based on a colour scale (Es) that comprises the seven-point thermal sensation scale of ASHRAE 55 
(ASHRAE 55, 2010) and considers the occupants' thermal sensation (Con). It uses air temperature and wet-bulb temperature as data inputs, and reproduces the results of the thermal pattern space, returning a dimensionless value in a range from -3 to 3 , following the same scheme as the ASHRAE thermal sensation scale. The formula used to determine EsConTer is:

EsConTer $=-3.75+0.103\left(\mathrm{~T}_{\mathrm{a}}+\mathrm{T}_{\mathrm{w}}\right)$

where, $\mathrm{T}_{\mathrm{a}}\left({ }^{\circ} \mathrm{C}\right)$ is the air temperature and $\mathrm{T}_{\mathrm{w}}(\%)$ the wet-bulb temperature.

The ASHRAE thermal sensation scale is based on the heat balance of the human body, and represents human thermal perception through seven points: +3 (hot), +2 (warm), +1 (slightly warm), 0 (neutral), -1 (slightly cool), -2 (cool), -3 (cold). Considering the ASHRAE seven-point thermal sensation scale, the EsConTer index follows the same scheme, although it is represented by a colour scale from -3 to +3 . As can be seen in Fig. 2 , the darkest blue colour corresponds to -3 , which means an extremely cold thermal sensation, while +3 , represented by the darkest red colour, means an extremely hot thermal sensation. The other colours are linked to intermediate values, with 0 associated with a neutral thermal comfort sensation, equidistant to the colours at the extremes of the scale.

The colour scale represented in Fig. 2 can also be used to investigate the thermal perception of the occupants of a specific environmental thermal space (that is, the workers' subjective sensations), allowing responses between two values, and not limited to only seven digits as with the ASHRAE thermal sensation seven-point scale.

To validate the results of EsConTer index, the THI index was applied. The THI was created by Thom (1959) and later modified by Nieuwolt (Nieuwolt, 1977). Initially, using Thom's approach, this index was calculated from wet-bulb temperature and air temperature, but Nieuwolt modified it, replacing wet-bulb temperature with relative humidity. This change was made in order to facilitate the implementation and evaluation of the index. The formula used to determine $\mathrm{THI}$ is:

$\mathrm{THI}=0.75 \mathrm{~T}_{\mathrm{a}}+\mathrm{T}_{\mathrm{a}}\left(\frac{\mathrm{RH}}{500}\right)$

where $\mathrm{T}_{\mathrm{a}}$ is the air temperature $\left({ }^{\circ} \mathrm{C}\right)$ and $\mathrm{RH}$ the relative humidity (\%).

Considering the subjectivity associated with thermal comfort, there are different intervals in the literature to support the interpretation of this index. The present study followed the THI limits adopted by Talaia et al. (Talaia et al., 2013), as shown in Table 1.

Other widely used models which evaluate thermal sensation are the Predicted Mean Vote (PMV) and Predicted Percentage Dissatisfied (PPD). The first of these, PMV, was created by Fanger (Fanger, 1972) and predicts the mean response in terms of thermal comfort of a larger group of people exposed to certain thermal conditions over a long period of time (Castilla et al., 2011), according to the ASHRAE thermal sensation scale. The PPD index, meanwhile, is a quantitative measure of the thermal comfort of a group of people which represents the percentage of individuals dissatisfied when exposed to certain thermal conditions.

According to ISO 7730 (2006), the formula for calculating the

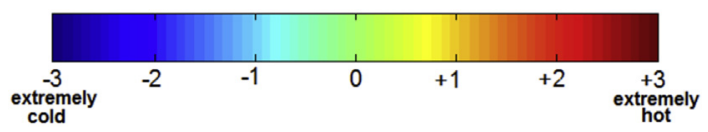

Fig. 2. Thermal sensation colour scale.
Table 1

Thermal sensation limits.

\begin{tabular}{ll}
\hline THI & Thermal sensation \\
\hline THI $<8$ & too cool \\
$8 \leq \mathrm{THI}<21$ & sun needed for comfort \\
$21 \leq \mathrm{THI}<24$ & COMFORTABLE \\
$24 \leq \mathrm{THI}<26$ & wind needed for comfort \\
$26 \leq \mathrm{THI}$ & too hot \\
\hline
\end{tabular}

PPD index is given by:

$\left.\mathrm{PPD}=100-95 e^{\left[-\left(0.03353 P M V^{4}+0.2179 P M V^{2}\right)\right.}\right]$

In an ideal situation and regarding Liang and Du (2005) and ASHRAE (ASHRAE, 2001), a PMV equal to zero is expected, combining optimal hygrometric and personal parameters. Nevertheless this scenario is impossible to achieve, as it requires $100 \%$ of the individuals in a group to feel satisfied by the surrounding thermal conditions. Addressing this reflection, it was therefore necessary to employ the admissible limits used by the PMV and PPD indexes to characterize an area as a comfort zone, namely (ISO 7730, 2006):

- A category: PPD $<6 \%$ and $-0.2<\mathrm{PMV}<+0.2$;

- B category: PPD $<10 \%$ and $-0.5<$ PMV $<+0.5$;

- C category: PPD $<15 \%$ and $-0.7<$ PMV $<+0.7$.

The PMV-PPD model presents an empirical relationship between the percentage of people dissatisfied (PPD) with a thermal environment using a function of the PMV. The PMV index is based on the heat balance of the human body, and therefore its calculation is not easy and to apply directly. In the present study, the PPD formula was modified, with the PMV input value replaced by the EsConTer value, as shown Equation (4).

$\left.\mathrm{PPD}=100-95 e^{\left[-\left(0.03353 E_{\text {SConTer }}^{4}+0.2179 \text { EsConTer }^{2}\right)\right.}\right]$

\subsection{Matlab algorithms and colour maps}

With the aim of facilitating the processing analysis and the interpretation of the results, the three indexes used in this work THI, EsConTer, and PPD - were programmed in MatLab.

Firstly, the data collected using measuring instruments, specifically the air temperature, relative humidity and the wet-bulb temperature, was organized in Microsoft Excel.

Next, the MatLab algorithm (i) read the input data present in the Microsoft Excel; (ii) calculated the average value for each point of observation, using different measurements taken at each local point; and consequently (iii) reproduced the results of each variable (e.g., air temperature, relative humidity) or index (e.g., THI, EsConTer, PPD), according to a statistical method which minimizes the squared error between two observation points.

Based on this data, the MatLab algorithm generated the colour maps, in order to facilitate interpretation of the results produced by the indexes or variables. In the present practical cases, the generated colour maps represent the average pattern of (1) air temperature, (2) relative humidity, (3) THI index, (4) EsConTer index, and (5) PPD index.

In each of the maps, the colour scale on the right side represents the range of possible values for each variable or index under study, with the respective colour pattern. The $\mathrm{x}$ and $\mathrm{y}$ axes represent the dimensions of the study areas in metres $(\mathrm{m})$, mapping the data onto the industry layouts.

On the basis of the generated colour maps, it is possible to apply a specific zoom algorithm to easily identify the most critical areas, 
Table 2

Anthropometric data for the subjects.

\begin{tabular}{|c|c|c|c|c|c|}
\hline Sex & Number of subjects & Years of age & Height (m) & Weight (kg) & Industry \\
\hline Male & 4 & $43.4 \pm 8.7$ & $1.68 \pm 0.09$ & $79.7 \pm 6.6$ & IND_1 \\
\hline Female & 1 & & & & \\
\hline Male & 6 & $47.7 \pm 11.6$ & $1.64 \pm 0.12$ & $82.2 \pm 8.2$ & IND_2 \\
\hline Female & 2 & & & & \\
\hline
\end{tabular}

i.e., the most uncomfortable areas regarding thermal discomfort. Additionally, other maps regarding the average thermal pattern with standard deviation were also created, using specific algorithms in MatLab, thereby displaying the situation closest to the most uncomfortable scenario experienced during the period of the study.

\subsection{Measurement of workers' thermal sensation}

Another important aspect used to evaluate thermal environments in an indoor space is the investigation of the thermal sensation of its occupants.

Human thermal perception stems from thermal sensation, a reaction of the human body caused by the surrounding environment (Yao et al., 2009). Thermal sensation is influenced by several factors which affect the response of a person when exposed to a specific environment. These factors can be grouped in two categories: personal factors (characteristics of the occupants, such as metabolic rate and clothing insulation), and environmental factors (conditions of the thermal environment, including air temperature, mean radiant temperature, air speed, and relative humidity).

Regarding personal factors, these can differ from person to person, which justifies the subjectivity that is usually associated with thermal sensation. This concept has mainly been studied through surveys which draw on the ASHRAE seven-point thermal sensation scale, where the respondents indicate which one of the seven values of this scale best corresponds to their real thermal sensation at the time they are surveyed (Liu et al., 2012; Chow et al., 2010).

As mentioned previously, the EsConTer index was used to predict the occupants' thermal sensation. After identifying the critical areas in terms of thermal comfort, based on the methodology described above, all the people who work at workstations located in these areas were surveyed using a thermal sensation colour scale (see Fig. 2). The anthropometric data for the subjects involved are listed in Table 2.

The study was approved by IND_1 Ethical Board and by IND_2 Ethical Board, and all subjects involved were informed and their consents were obtained. Workers were asked to respond with a tag at the position that best corresponded to their thermal sensation at the time they were surveyed. Training in filling out the survey was given to the workers before its application.

In order to compare the thermal sensation with the thermal environment and to measure worker's predicted thermal sensation, air temperature and relative humidity data were also collected from the workstation at the time of inquiry, using the Testo 435-4 measuring instruments.

The surveys and measurements were made at four times during the day: in the morning at 10 a.m. and 12 a.m., and in the afternoon at 2-3 p.m. and 4-5 p.m., at all critical workstations (five in IND_1 and eight in IND_2). These measurements at different times were done in order to understand the influence of the diurnal solar cycle on workers' thermal sensation during the day. Moreover, from the real thermal sensation and thermal environment variables, it was possible to perform measurements to validate the approximation of real data to the EsConTer index (predicted thermal sensation).

\section{Results and discussion}

The present section shows the results obtained in each industry studied, and their discussion. Initially, using colour maps, the average thermal pattern in the industrial spaces for spring will be presented, as well as the most uncomfortable workplaces in each studied space. Next, to understand the extremes in terms of thermal pattern in the period under analysis, colour maps showing the mean values plus standard deviation were generated. Finally, some discussion about the role of the EsConTer index in revealing thermal patterns in industrial interior spaces and in predicting their occupants' thermal sensation will also be presented.

\subsection{Thermal pattern of industrial spaces and the identification of the most critical workplaces}

Fig. 3 represents the average pattern of the air temperature and relative humidity variables for IND_1, using the colour maps generated by MatLab algorithms. The colour scale on the right side
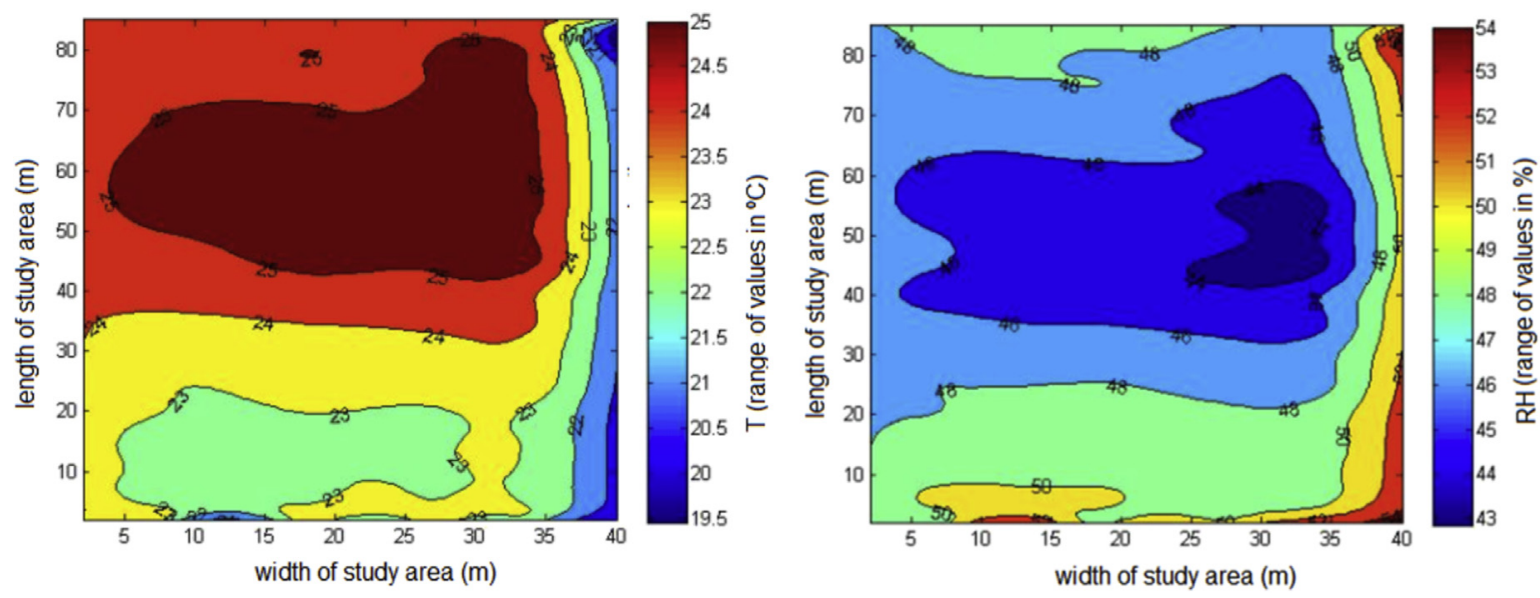

Fig. 3. Air temperature $\left({ }^{\circ} \mathrm{C}\right)$ average pattern (left) and relative humidity (\%) average pattern (right) for IND_1. 

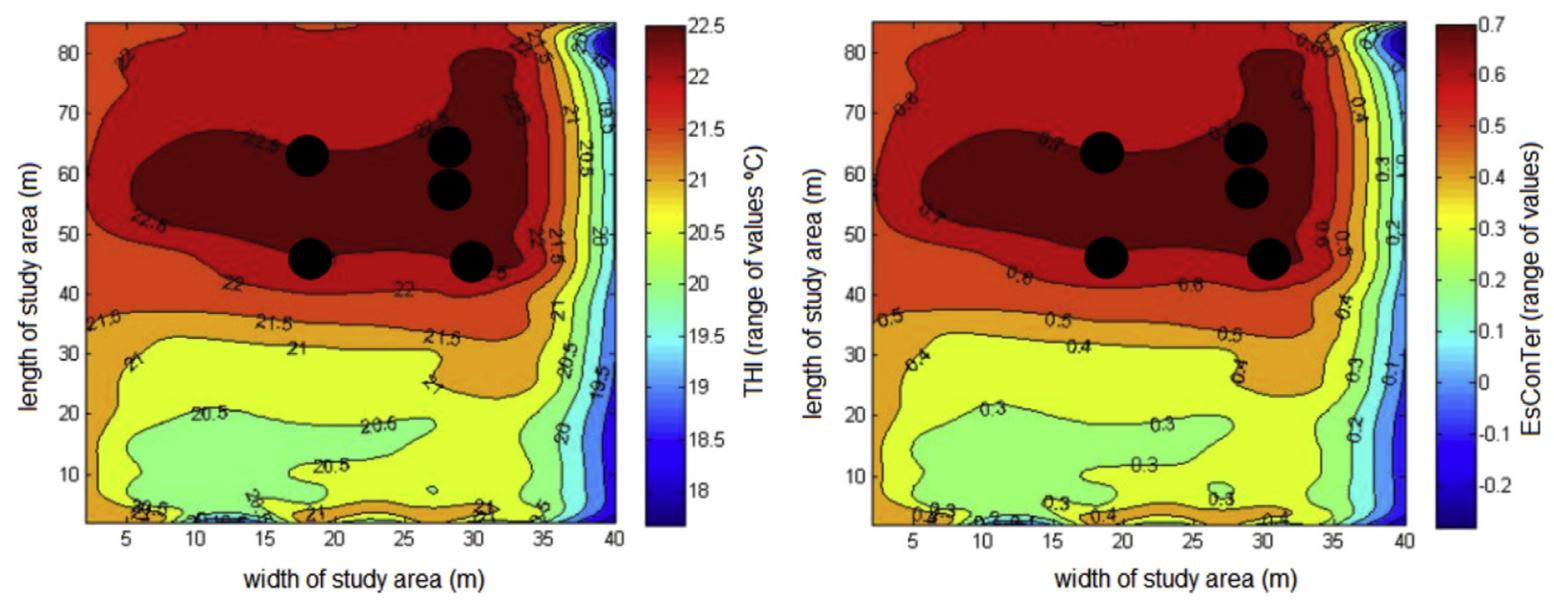

Fig. 4. Average thermal pattern represented by the THI $\left({ }^{\circ} \mathrm{C}\right)$ (left) and EsConTer (right) indexes for IND_1.

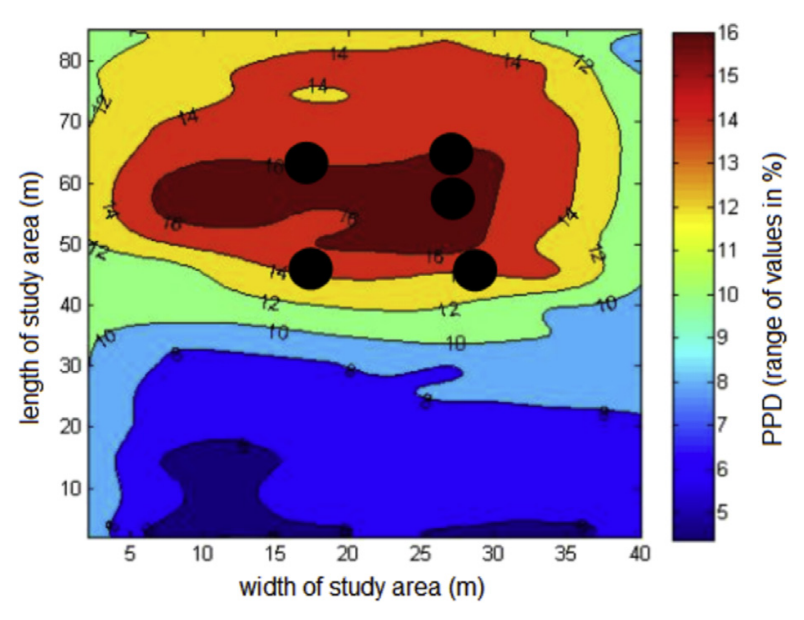

Fig. 5. Average thermal pattern by PPD (\%) for IND_1.

of each representation shows the range of possible values for each variable. For example, in the case of the air temperature, the values for the studied space range from $19.5{ }^{\circ} \mathrm{C}$ (minimum) to $25{ }^{\circ} \mathrm{C}$ (maximum). For the relative humidity, the range of values is from $43 \%$ (minimum) to $54 \%$ (maximum). The $\mathrm{x}$ and $\mathrm{y}$ axes represent the dimensions of the spaces in metres, mapping the data onto the industry layouts.

As expected, the regions affected by higher air temperatures are the regions affected by lower relative humidity values.

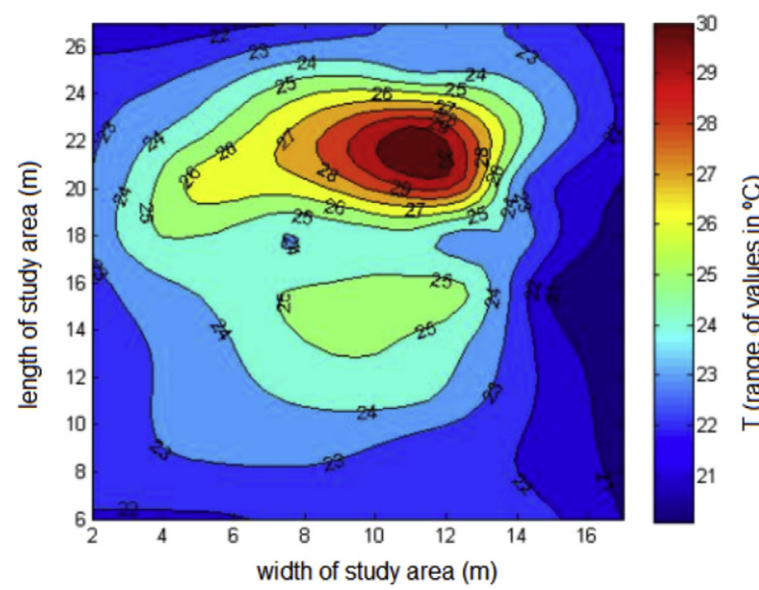

Fig. 4 presents the results of the THI and EsConTer indexes for IND_1, based on colour maps that are in agreement with the results reported by Fig. 3.

In the representations the darkest red colour corresponds to the most uncomfortable area, associated with higher thermal heat stress.

Comparing the results reported in Fig. 3 with those of Fig. 4, it is possible to verify that the same critical area is suggested. Both of the indexes represented in Fig. 4 are in agreement, since the thermal lines designated in these maps almost coincide. Indeed, the values obtained with the application of THI and EsConTer reveal a significant correlation coefficient of 0.963 .

The five black circles on the colour maps represent the most critical workstations of permanent workers, when the zoom algorithm was applied. These workstations are manual and automatic welding stations, oven entrances, and assembly stations near hot bath stations, and are affected by thermal environments of between $21.5^{\circ} \mathrm{C}$ and $22.5^{\circ} \mathrm{C}$, according to the THI, and between 0.5 and 0.7 according to the EsConTer index.

Fig. 5 represents the PPD index, showing the percentage of unsatisfied individuals in this interior space. On this scale, dissatisfaction levels for the selected workstations are between $14 \%$ and 16\%. Compared with the PMV-PPD model, this result shows a curious agreement between EsConTer-PPD (where PMV is replaced by EsConTer) and PMV-PPD. According to the PMV-PPD model (ISO 7730 (2006), the scenario represented falls under category C limits, i.e., it is at the border of the comfort zone.

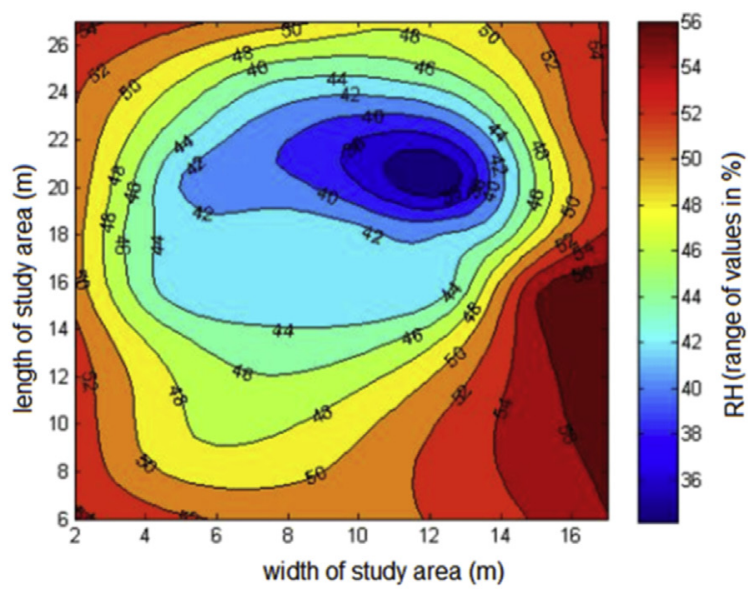

Fig. 6. Air temperature $\left({ }^{\circ} \mathrm{C}\right.$ ) average pattern (left) and relative humidity (\%) average pattern (right) for IND_2. 



Fig. 7. Average thermal pattern by THI $\left({ }^{\circ} \mathrm{C}\right)$ (left) and EsConTer index (right) for IND_2.

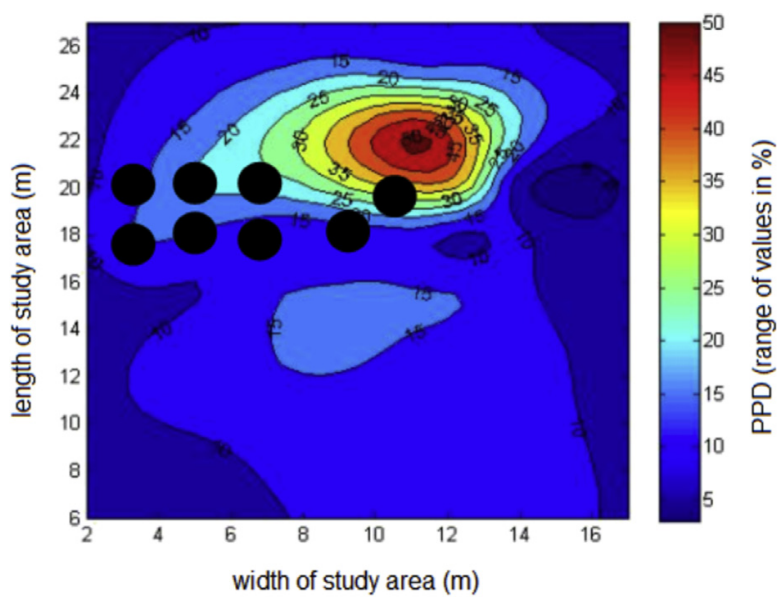

Fig. 8. Average thermal pattern by PPD (\%) for IND_2.

The colour maps reflecting the average pattern of air temperature and relative humidity for IND_2 are presented in Fig. 6. As in the case of IND_1, the areas affected by higher temperatures are the areas with lower relative humidity values. So, this area, affected by $28^{\circ} \mathrm{C}-30{ }^{\circ} \mathrm{C}$ and $35 \%-40 \%$ is considered the most critical region regarding thermal discomfort. As this area is occupied by work machinery (industrial ovens), it is not considered a working area.

The colour maps relating to THI and EsConTer are represented in Fig. 7. Once again, regarding Fig. 7, both thermal indexes seem to be in agreement because of the concordance of their thermal lines. In terms of thermal index interpretation, the most critical areas, coloured in red, are under thermal discomfort. THI values are between $24^{\circ} \mathrm{C}$ and $26^{\circ} \mathrm{C}$ (wind needed for comfort), and EsConTer values are around 1.0 and 1.4 (slightly warm to warm).

It is noted that the identified workstations do not coincide exactly with the areas affected by the highest levels of thermal stress because some of the areas in this industry are free from occupied workstations, representing the positions of machines where nobody works continuously. However, the selected workstations, represented by the eight black circles and defined by the zoom algorithm, are the closest workplaces to this area. These workstations are affected by thermal environments of between $21{ }^{\circ} \mathrm{C}$ and $24{ }^{\circ} \mathrm{C}$, according to the THI, and between 0.4 and 1.0 according to the EsConTer index. These workstations are hot cutting stations, working areas near oven entrances (where glass is removed with a rod), and presses.

Fig. 8 represents the PPD index, showing the percentage of dissatisfied individuals in this inner space of IND_2.

The PPD index is also in agreement with EsConTer (PMV) due to
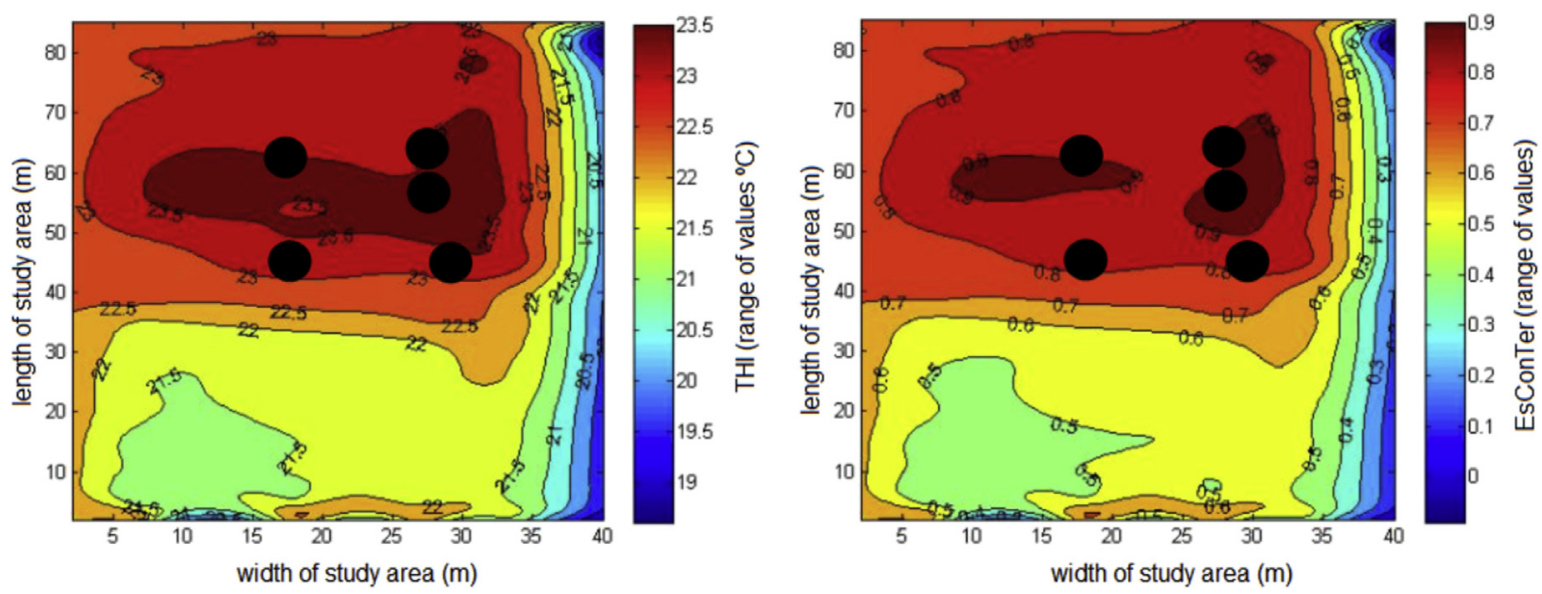

Fig. 9. Average thermal pattern plus standard deviation by THI $\left({ }^{\circ} \mathrm{C}\right)$ (left) and EsConTer index (right) for IND_1. 




Fig. 10. Average thermal pattern plus standard deviation by PPD (\%) for IND_1.

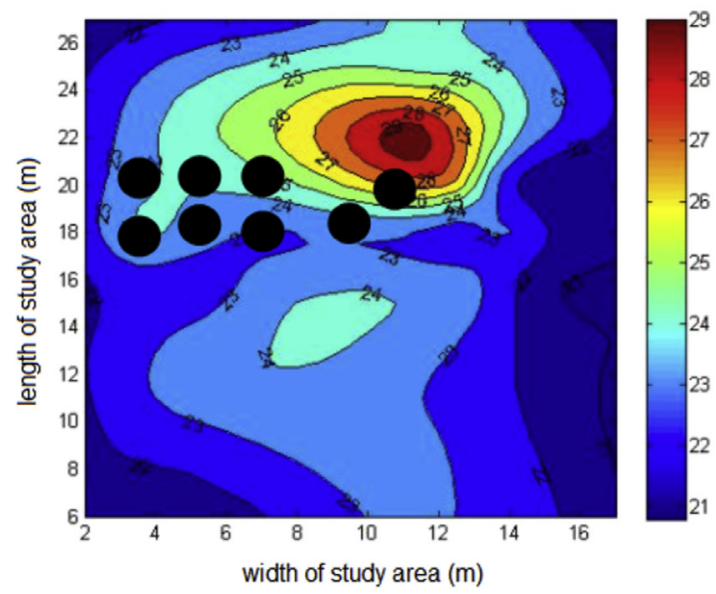

\subsection{The thermal pattern closest to the most uncomfortable scenario}

The colour maps that represent IND_1's average thermal patterns plus standard deviation, which characterize the closest scenario to the most uncomfortable environment during the study period, can been seen in Figs. 9 and 10.

As expected, these colour maps represent greater thermal discomfort, as in both the THI and the EsConTer indexes the values rise, to over $24{ }^{\circ} \mathrm{C}$ and 1.0 respectively. Once again, THI and EsConTer index behaviour concurred, as well as the relationship between the EsConTer and PPD indexes. Under these thermal environment conditions, the percentage of dissatisfied occupants rose to around $22 \%$.

Fig. 11 represents the average thermal pattern plus standard deviation of the interior space of IND_2. As expected, the thermal pattern in Fig. 11 suggests greater thermal discomfort than that revealed in Fig. 7; nevertheless, both indexes are also in agreement. The most critical area showed in these colour maps, represented by red shading, indicates the position of the industrial oven.

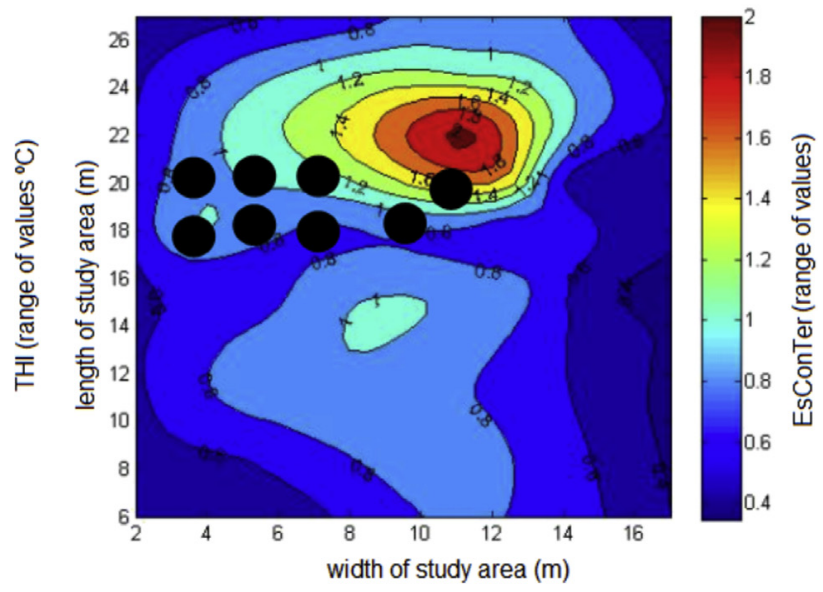

Fig. 11. Average thermal pattern plus standard deviation by THI $\left({ }^{\circ} \mathrm{C}\right)$ (left) and EsConTer index (right) for IND_2.

its concordance with the PMV-PPD model. So, regarding these results, in some workstations the thermal environment is at the limit of slight thermal stress, suggesting a percentage of workers dissatisfaction, under these conditions, of between $10 \%$ and $30 \%$.

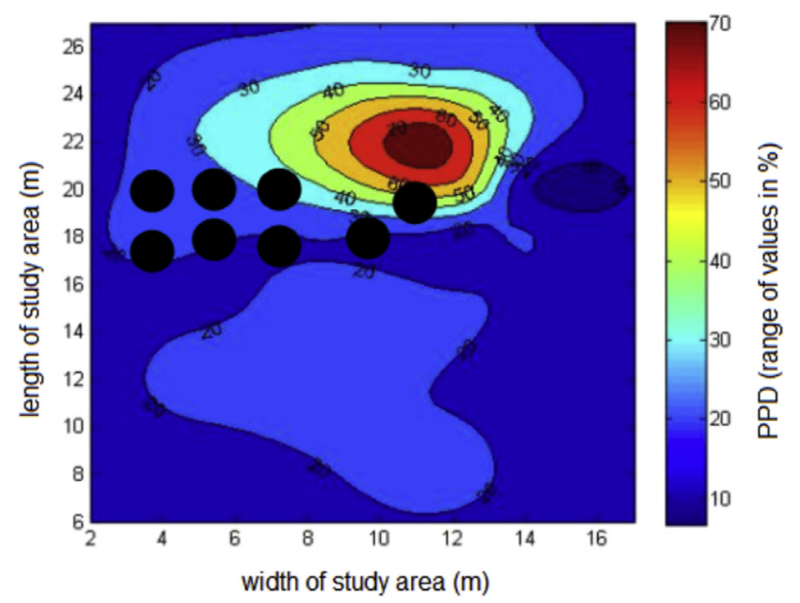

Fig. 12. Average thermal pattern plus standard deviation by PPD (\%) for IND_2.
Fig. 12 represents the PPD thermal pattern plus standard deviation. Beyond the picture revealed by direct measurement, this figure shows a higher percentage of dissatisfied occupants (around $20 \%-40 \%$ ) than the scenario shown in Fig. 8, as expected, due to the warmer thermal pattern found through the inclusion of standard deviation.

\subsection{The simplicity of the EsConTer index in revealing thermal patterns of industrial interior spaces}

The EsConTer index was demonstrably in agreement with THI, taking into account the correlation that was found in the colour maps generated in both case-studies, IND_1 and IND_2. The correlation coefficient between these two thermal indexes is very near to 1, which shows that EsConTer is a good index for predicting the thermal pattern in an indoor space. Moreover, from the colour maps applied to both indexes it was possible to identify the most critical areas, i.e., the most uncomfortable areas in terms of thermal environment. Thus, the colour maps seemed to provide an easy and intuitive way to interpret the thermal patterns of indoor spaces, allowing the observer to identify the most uncomfortable areas in order to prompt faster corrective actions.

Figs. 13 and 14 are examples of measurements over the course of one day, where the indoor and outdoor thermal environment 


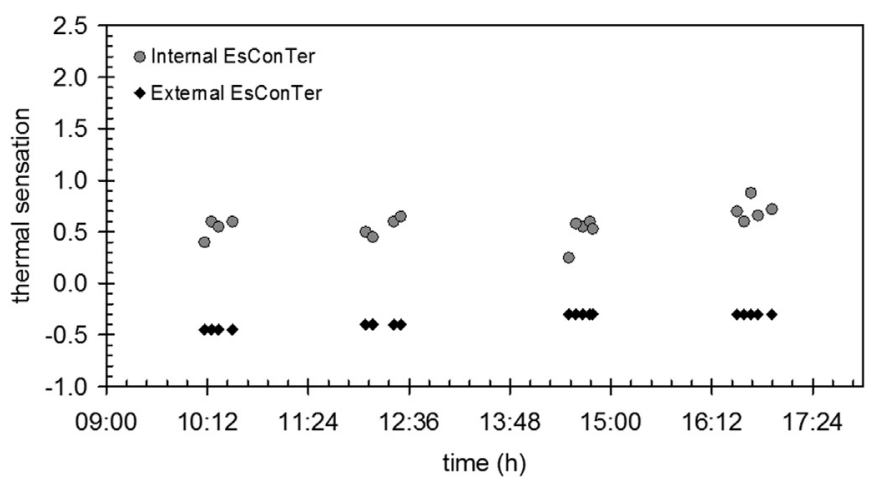

Fig. 13. Internal and external thermal environment in IND_1.

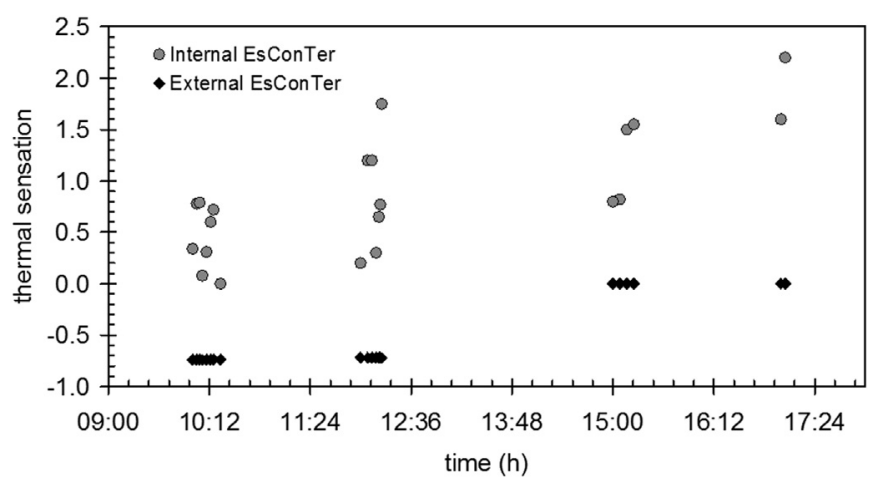

Fig. 14. Internal and external thermal environment in IND_2.

changes in both industries can be viewed. The internal EsConTer represents the thermal environment in the interior space (indoor measurements), and the external EsConTer represents the thermal environment outside the studied indoor spaces (outdoor measurements).

Comparing the two scenarios, it is possible to verify that the thermal pattern of IND_2 is warmer than that of IND_1. Also, the indoor space of IND_2 showed a less consistent thermal pattern than IND_1. This situation is due to the industrial context of the two facilities, and is perhaps related to IND_1 having different infrastructure (walls, roof, and insulation) to IND_2.

Comparing the evolution of the internal and external EsConTer values in both areas studied, it is possible to confirm the influence of the external environment on the inner spaces in terms of thermal pattern. The thermal environment of the inner space followed variations in the outdoor environment: as the external EsConTer approaches 0 (the value that represents optimal comfort), the internal EsConTer rises and becomes more uncomfortable.

Regarding the diurnal cycle, it was interesting to observe the kind of greenhouse effect that occurs in both indoor spaces, mainly right after noon. Because of this phenomenon, the thermal discomfort gradually increases over time, reaching peak discomfort at around 5 p.m. for both industries.

Given that EsConTer index results are based on the ASHRAE seven-point thermal sensation scale, this index surprisingly demonstrated itself capable of predicting the PMV index, even taking into account different input parameters. As a result, use of the EsConTer index is also suggested for predicting the workers' thermal sensation.

\subsection{EsConTer index as a tool to predict thermal sensation of the occupants of interior spaces}

Figs. 15 and 16, like Figs. 13 and 14, show the indoor and outdoor thermal environment, represented by internal EsConTer and external EsConTer, with the addition of the workers' subjective thermal sensations, collected using the thermal sensation colour scale. Five workers in IND_1 and eight workers in IND_2 voluntarily participated in this experiment (see Table 2).

Through Figs. 15 and 16, the correlation between internal EsConTer (environmental parameters collected using measuring instruments) and workers' thermal sensation (subjective thermal sensation collected using the thermal sensation colour scale) can be visualized. The two variables have a correlation coefficient of 0.9316; thus, EsConTer also reliably predicts workers' actual thermal sensation, confirming the results of the EsConTer-PPD.

Beyond that, it is also possible to visualize the unequivocal subjectivity associated with thermal sensation, as under the same environment workers clearly show different thermal sensations. Moreover, as expected, the workers' thermal sensation in IND_2 is more inconsistent than in IND_1, showing that even workers' thermal sensation follows environmental thermal changes in time.

In general terms, and considering the results of the study described, it is possible to conclude that the methodology applied in this work represents a good model for thermal stress risk evaluation, minimizing the need for difficult and time-consuming investigations to identify thermal comfort problems in workplaces. The colour maps generated by MatLab algorithms also proved to be a useful tool for visualizing the thermal pattern of an indoor environment, and consequently produced useful information for solving thermal comfort problems.



Fig. 15. Internal and external thermal environment and workers' real thermal sensation in IND_1.

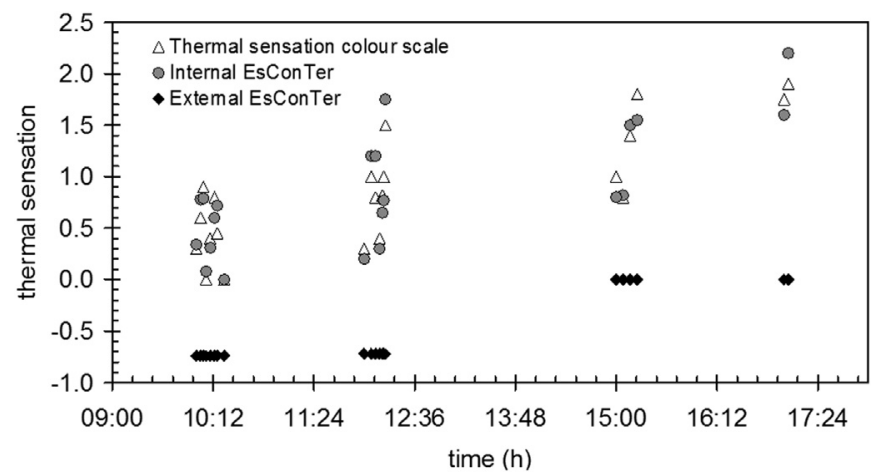

Fig. 16. Internal and external thermal environment and workers' real thermal sensation in IND_2. 


\section{Conclusions}

The results of this study demonstrate the capability of predicting the average thermal pattern of an industrial inner space and identifying the most critical areas affected by thermal environments, using a simplified model based on the EsConTer index. Indeed, all the results confirmed that the EsConTer index is in agreement with the THI as well as with the PMV, insofar as the PMV-PPD model is aligned with the EsConTer-PPD. Additionally, the EsConTer index was also in agreement with workers' actual thermal sensation, suggesting its capacity to accurately predict the thermal sensation of the occupants of indoor spaces. The EsConTer index measurements only made use of digital measuring instruments (Testo 435-4 and Center 317-temperature humidity meter) and the thermal sensation colour scale; this shows that thermal environment studies can be performed using inexpensive instruments, and for this reason it should be applicable in industries and other workplaces.

Neither of the industrial facilities (IND_1 and IND_2) where this study was performed had thermal environment control tools as part of their everyday practices, although the results were appreciated by the Health and Safety Department of each industry in order to develop measures that might improve the occupational health of the occupants of these spaces to prevent work accidents and work-related disorders.

Additionally, the colour maps seemed a useful and intuitive means of highlighting the most vulnerable areas as well as the dynamic of the thermal environment in an interior space, thus offering an easy reading and interpretation tool for any decisionmaker. So, regarding the information from such colour maps and workers' thermal sensation given by the EsConTer index, workrelated disorders may be minimized through corrective actions which take results from this index into consideration. In this sense, corrective actions, including adjusting thermal environment conditions, workers' exposure time to such environments, and the type of tasks/functions/movements developed in the workplaces in such areas, should be applied in order to avoid possible work-related disorders.

Accordingly, the methodology applied in this work offers a sound model for thermal stress risk evaluation, minimizing difficult and time-consuming investigations to identify thermal comfort problems in workplaces. The coloured maps generated by MatLab algorithms proved to be a useful tool to visualize the thermal pattern of an environment, and consequently produce useful information for solving thermal comfort problems.

The study results are positive and also very important as they constitute the first data in this topic. However, it should be noted that the data was collected for just one season (spring) as well as the small sample involved in the experiment, present some limitations. To address these limitations, long-term studies with larger sample size are needed. Thus future work is suggested which takes into account all the seasons of the year, and defines the thermal pattern for each season in order to trigger faster corrective measures, for better work and safety conditions. The application of the present methodology is further proposed in other industrial contexts and in cold thermal environments to understand the behaviour of the thermal indexes used under those conditions. A study focused on workers' thermal sensation, regarding personal variables such as clothing insulation (clo), metabolism, gender, or age, and productivity and quality indexes are other long-term goals regarding the utilization of the EsConTer index.

\section{Conflict of interest statement}

The authors point out that there was no conflict of interest when doing this research in an industrial environment. The sole purpose is to contribute to the improvement of scientific knowledge.

\section{Acknowledgements}

We acknowledge the workers who participated in this study by answering the surveys, as well as the board of directors of the two industries, who facilitated us in developing this investigation.

\section{References}

Akimoto, T., Tanabe, S., Yanai, T., Sasaki, M., 2010. Thermal comfort and productivity - evaluation of workplace environment in a task conditioned office. Build Environ. 45, 45-50. http://dx.doi.org/10.1016/j.buildenv.2009.06.022.

Arezes, P.M., Neves, M.M., Teixeira, S.F., Leão, C.P., Cunha, J.L., 2013. Testing thermal comfort of trekking boots: an objective and subjective evaluation. Appl. Ergon. 44, 557-565. http://dx.doi.org/10.1016/j.apergo.2012.11.007.

ASHRAE, 2001. In: Thermal Comfort. American Society of Heating, Refrigerating and Air-Conditioning Engineers, Englewood, Colorado USA.

ASHRAE 55, 2010. Thermal Environmental Conditions for Human Occupancy. American Society of Heating, Refrigerating and Air-Conditioning Engineers Atlanta, Georgia.

Bluyssen, P.M., Aries, M., van Dommelen, P., 2011. Comfort of workers in office buildings: the European HOPE project. Build. Environ. 46, 280-288. http:// dx.doi.org/10.1016/j.buildenv.2010.07.024.

Bröde, P., Błazejczyk, K., Fiala, D., Havenith, G., Holmér, I., Jendritzky, G., Kuklane, K. Kampmann, B., 2013. The Universal Thermal Climate Index UTCI compared to ergonomics standards for assessing the thermal environment. Ind. Health 51 $16-24$.

Castilla, M., Álvarez, J.D., Berenguel, M., Rodríguez, F., Guzmán, J.L., Pérez, M., 2011 A comparison of thermal comfort predictive control strategies. Energy Build. 43, 2737-2746. http://dx.doi.org/10.1016/j.enbuild.2011.06.030.

Chiasson, M.-ève, Imbeau, D., Aubry, K., Delisle, A., 2012. Comparing the results of eight methods used to evaluate risk factors associated with musculoskeletal disorders. Int. J. Ind. Ergon. 42, 478-488. http://dx.doi.org/10.1016/ j.ergon.2012.07.003.

Chow, T.T., Fong, K.F., Givoni, B., Lin, Z., Chan, A.L.S., 2010. Thermal sensation of Hong Kong people with increased air speed, temperature and humidity in airconditioned environment. Build. Environ. 45, 2177-2183. http://dx.doi.org/ 10.1016/j.buildenv.2010.03.016.

Costa, B., Vieira, E., 2010. Risk factors for work-related musculoskeletal disorders. A Syst. Rev. Recent Longitud. Stud. 53, 285-323. http://dx.doi.org/10.1002 ajim.20750.

Cox, C., 2005. Health Optimisation Protocol for Energy-efficient Buildings. TNO, Delft, The Netherlands.

De Giuli, V., Zecchin, R., Corain, L., Salmaso, L., 2014. Measured and perceived environmental comfort: field monitoring in an Italian school. Appl. Ergon. 45, 1035-1047. http://dx.doi.org/10.1016/j.apergo.2014.01.004.

Emmanuel, R., 2005. Thermal comfort implications of urbanization in a warmhumid city: the Colombo Metropolitan Region (CMR), Sri Lanka. Build. Environ. 40, 1591-1601. http://dx.doi.org/10.1016/j.buildenv.2004.12.004.

Escorpizo, R., 2008. Understanding work productivity and its application to workrelated musculoskeletal disorders. Int. J. Ind. Ergon. 38, 291-297. http:// dx.doi.org/10.1016/j.ergon.2007.10.018.

Fanger, P., 1972. Thermal Comfort, second ed. McGraw-Hill, New York.

Felix, V.B., Moura, D., Pereira, M.L., Tribess, A., 2010. Evaluation of thermal comfort in surgical environments using Fanger's method and equivalent temperatures. Ambient. Construído 10, 69-78.

Guimarães, L.B. de M., Anzanello, M.J., Ribeiro, J.L.D., Saurin, T.A., 2015. Participatory ergonomics intervention for improving human and production outcomes of a Brazilian furniture company. Int. J. Ind. Ergon. 49, 97-107. http://dx.doi.org/ 10.1016/j.ergon.2015.02.002.

Huizenga, C., Abbaszadeh, S., Zagreus, L., Arens, E., 2006. In: Air Quality and Thermal Comfort in Office Buildings: Results of a Large Indoor Environmental Quality Survey. Proceedings of Healthy Buildings, Lisbon, pp. 393-397.

IEA, 2014. International Ergonomics Association [WWW Document]. What is Ergon. Defin.

ISO 7243, 1989. In: Hot Environments - Estimation of the Heat Stress on Working Man, Based on WBGT-index (wet bulb temperature). International Standardization Organization, Geneva, Suisse.

ISO 7726, 2001. In: British st (Ed.), Ergonomics of the Thermal Environment Intruments for Measuring Physical Quantities.

ISO 7730, 2006. In: Ergonomics of Thermal Environment - Analytical Determination and Interpretation of Thermal Comfort Using Calculation of PMV and PPD Indeces and Local Thermal Comfort Criteria. International Standards Organization.

Jackson, L., Rosenberg, H., 2010. Preventing heat-related illness among agricultural workers. J. Agromedicine 15, 200-215. http://dx.doi.org/10.1080/ 1059924X.2010.487021.

Lan, L., Wargocki, P., Lian, Z., 2011. Quantitative measurement of productivity loss due to thermal discomfort. Energy Build. 43, 1057-1062. http://dx.doi.org/ 
10.1016/j.enbuild.2010.09.001.

Lee, D.H.K. Henschel, A, 1963, Evaluation of Thermal Environment in Shelters Department of Health, Education and Welfare, Public Health Service, Division of Occupational Health, Washington, DC.

Liang, J., Du, R., 2005. Thermal Comfort control based on neutral network of HVAC application. In: 2005 IEE Conference on Control Applications. Toronto, Canada.

Liu, J., Yao, R., Wang, J., Li, B., 2012. Occupants' behavioural adaptation in workplaces with non-central heating and cooling systems. Appl. Therm. Eng. 35, 40-54. http://dx.doi.org/10.1016/j.applthermaleng.2011.09.037.

Matzarakis, a, Mayer, H., Iziomon, M.G., 1999. Applications of a universal thermal index: physiological equivalent temperature. Int. J. Biometeorol. 43, 76-84. http://dx.doi.org/10.1007/s004840050119.

Mohamed, S., Srinavin, K., 2002. Thermal environment effects on construction workers' productivity. Work Study 51, 297-302. http://dx.doi.org/10.1108/ 00438020210441849.

Morgado, M., Teixeira, L., Talaia, M., 2015. Creating productive workers in industria context from the Definition of Thermal Comfort. Int. J. Ind. Eng. Manag. 6, $75-84$.

Nieuwolt, S., 1977. Tropical Climatology. London.

Ogg, M., 2011. Introduction to the safe patient handling and movement Series. AORN J. 93, 331-333. http://dx.doi.org/10.1016/j.aorn.2010.12.004.

Oliveira, A.V.M., Gaspar, A.R., André, J.S., Quintela, D.A., 2014. Subjective analysis of cold thermal environments. Appl. Ergon. 45, 534-543. http://dx.doi.org 10.1016/j.apergo.2013.07.013.

Riniolo, T.C., Schmidt, L.A., 2006. Chronic heat stress and cognitive development: an exemple of thermal conditions influencing human development. Dev. Rev. 26 , $277-290$.

Roman-liu, D., 2013. External load and the reaction of the musculoskeletal system a conceptual model of the interaction. Int. J. Ind. Ergon. 43, 356-362. http:// dx.doi.org/10.1016/j.ergon.2013.04.002.

Talaia, M. Meles, B., Teixeira, L., 2013. Evaluation of the thermal comfort in workplaces - a study in the metalworking industry. In: Arezes, P., Baptista, J.S.
Barroso, M.P., Carneiro, P., Cordeiro, P., Costa, N., Melo, R., Miguel, A., Perestrelo, G. (Eds.), Occupational Safety and Hygiene. Taylor \& Francis Group, London, pp. 473-477.

Talaia, M., Simões, H., 2009. EsConTer: um índice de avaliação de ambiente térmico. In: V Congresso Cubano de Meteorologia. Somet-Cuba, Sociedade de Meteorologia de Cuba, pp. 1612-1626.

Teixeira, L., Talaia, M., Morgado, M., 2014. 2014. Evaluation of indoor thermal environment of a manufacturing industry. In: Occupational Safety and Hygiene II - Selected Extended and Revised Contributions from the International Symposium Occupational Safety and Hygiene, SHO, pp. 553-558.

Thom, E.C., 1959. The Discomfort Index. Weatherwise, Boston, pp. 57-60.

Wagner, a., Gossauer, E., Moosmann, C., Gropp, T., Leonhart, R., 2007. Thermal comfort and workplace occupant satisfaction - results of field studies in German low energy office buildings. Energy Build. 39, 758-769. http:// dx.doi.org/10.1016/j.enbuild.2007.02.013.

Wisner, A., 1992. A Antropotecnologia. Estud. Avançados 6. http://dx.doi.org/ 10.1590/S0103-40141992000300003.

Yao, R., Li, B., Liu, J., 2009. A theoretical adaptive model of thermal comfort Adaptive Predicted Mean Vote (aPMV). Build. Environ. 44, 2089-2096. http:// dx.doi.org/10.1016/j.buildenv.2009.02.014.

Yigit, A., Atmaca, I., Arslanoglu, N., Sivrioglu, K., 2015. Experimental investigation of the effect of thermal comfort parameters on cervical range of motion. Int. J. Ind. Ergon. 50,1-8. http://dx.doi.org/10.1016/j.ergon.2015.08.009.

Zare, M., Bodin, J., Cercier, E., Brunet, R., Roquelaure, Y., 2015. Evaluation of ergonomic approach and musculoskeletal disorders in two different organizations in a truck assembly plant. Int. J. Ind. Ergon. 50, 34-42. http://dx.doi.org/10.1016/ j.ergon.2015.09.009.

Zhou, L., Wei, J., Zhao, D., 2014. Human and Ecological risk Assessment: detecting the Impacts of Socioeconomic factors on Regional Severity of work- related Casualties in China. Hum. Ecol. Risk Assess. An Int. J. 20, 1469-1490. http:// dx.doi.org/10.1080/10807039.2014.892361. 